University of Nebraska - Lincoln

DigitalCommons@University of Nebraska - Lincoln

November 2002

\title{
"Getting into the mouths" of preschoolers: A method for obtaining buccal samples for later genotyping
}

\author{
K. A. Espy \\ University of Nebraska-Lincoln, kespy2@unl.edu
}

A. F. Hamby

Follow this and additional works at: https://digitalcommons.unl.edu/dcnlfacpub

Part of the Neurosciences Commons

Espy, K. A. and Hamby, A. F., "'"Getting into the mouths" of preschoolers: A method for obtaining buccal samples for later genotyping" (2002). Developmental Cognitive Neuroscience Laboratory - Faculty and Staff Publications. 17.

https://digitalcommons.unl.edu/dcnlfacpub/17

This Article is brought to you for free and open access by the Developmental Cognitive Neuroscience Laboratory at DigitalCommons@University of Nebraska - Lincoln. It has been accepted for inclusion in Developmental Cognitive Neuroscience Laboratory - Faculty and Staff Publications by an authorized administrator of DigitalCommons@University of Nebraska - Lincoln. 


\title{
"Getting Into the Mouths" of Preschoolers: A Method for Obtaining Buccal Samples for Later Genotyping
}

\author{
Kimberly Andrews Espy and Arlena F. Hamby \\ Department of Psychiatry \\ Southern Illinois University School of Medicine
}

A new procedure is described by which to obtain buccal samples from preschool children for research investigations that include genotyping.

Developmental neuropsychologists increasingly are exploring the role of genes as determinants of cognition in both clinically diagnosed and normally developing children. There are numerous behavioral genetic studies that have quantified nonspecific genetic influences on behavior, for example, determining the relative contributions of genetic and environmental factors in neuropsychiatric disorders. With the recent advances in molecular genetics, it is now possible to move beyond questions of relative heritability, that is, to directly link behavioral phenotype with specific genotypes. For neuropsychologists, of particular interest is the ability to examine genotypes for specific proteins in the brain involved in neurotransmitter function, for example, the D4 dopamine receptor (DRD4) or serotonin transporter (5-HTTLPR) genes. Molecular genetic analyses are attractive, as they offer the ability to understand brain-behavior relations at a level in addition to structure-function associations that currently are well studied with various neuroimaging procedures (see Gottlieb, 2001, for a discussion of the complexities of cross-level relations). Molecular genetic analyses of neurotransmitter-related genes already have engendered success in diverse investigations, such as those concerning adult smoking behavior (e.g., Sabol et al., 1999), neonatal temperament (e.g., Ebstein et al., 1998), and childhood attention deficit hyperactivity disorder

Requests for reprints should be sent to Kimberly Andrews Espy, Department of Psychiatry, Mailcode 6517, Southern Illinois University School of Medicine, Carbondale, IL 62901-6517. E-mail: kespy@siumed.edu 
(e.g., Cook et al., 1995). It is likely that even in children with structural brain damage as a consequence of brain injury, neurological disorder, or prenatal substance and environmental exposures, differential genetic vulnerability is an important source of individual differences in neuropsychological outcome.

Given the potentially widespread application of these techniques in normally developing and clinically identified populations, the challenge then becomes how to implement the procedures necessary to obtain the cellular material for subsequent genotyping from children. Molecular genetic analyses can be conducted on any tissue sample, as the individual's full genetic complement is contained in all cells. However, procedures used to collect cellular samples that are acceptable in the context of medical necessity differ from those that are appropriate in a research setting. For example, clinicians are well justified in using invasive or coercive procedures to ascertain whether a child suffers from Phenylketonuria, a genetic disorder for which early detection and treatment can mitigate later cognitive impairment. In contrast, ethical treatment of human research subjects requires minimizing both the invasiveness and risk of any procedure to participants. Whereas routine drawing and analysis of blood for genotyping may be acceptable for research study participants who are adults, such procedures would not be considered minimally invasive in normally developing children. Therefore, many research investigations with children have utilized buccal sampling, that is, where a small, toothbrush-like swab is rubbed gently inside the participant's cheek to collect surface epithelial cells. Buccal sampling yields sufficient cell samples for subsequent genotyping in the laboratory in most cases, although buccal samples often are more likely to be contaminated with other material than are blood samples, due to residua from food ingestion. In our laboratory, buccal sampling was used to better understand individual differences in executive functioning in an ongoing study with preschool children (e.g., Espy, Kaufmann, Glisky, \& McDiarmid, 2001), by exploring the contribution of variability in dopamine receptor genotype.

Although all parents of the young research participants consented to buccal sampling and later laboratory genotyping, the preschoolers did not cooperate consistently. The first participant was a 3-year-old boy who refused to open his mouth at the sight of the swab, despite his willing participation in all of the executive function tasks. In the same vein, out of the first five participants, $40 \%(n=2)$ refused and 20\% $(n=1)$ were not sufficiently cooperative to yield fully useable samples. Like the first participant, these preschool children also completed the other cognitive procedures. Therefore, it was obvious that the buccal sample collection method required modification. Several changes were considered. One parent commented that the examiner's white gloves worn during sample collection might have engendered fear in preschoolers, related to routine glove use in painful procedures conducted at the physician's office. However, the risk of fluid contact for the examiner was considered too high without gloving, because of potential fluid dispersion during buccal sampling in often-fidgety preschool children. Another par- 
ent offered to forcibly coerce the child by physically holding the child's mouth open for sampling; however, given the lack of medical necessity, this technique was not considered consistent with ethical principles for human subject protection that include voluntary assent in subjects who are minors.

From a developmental perspective, the problem is likely specific to preschool children, who define their autonomy on the basis of control of their bodies. We tried to design a procedure that took advantage of the natural curiosity of young children, while maintaining ethical obligations and requirements for subsequent molecular genetic analysis. Therefore, the "Lollipop Tasting Game" was developed. For this procedure, three clear mason jars were filled about halfway with water. Granulated sugar was added to each jar to make a noticeably sweet solution. Red food coloring was added to the first jar, a small bit of reconstituted lemon juice and yellow food coloring were added to the second jar, and finally, a bit of vanilla and blue food coloring were added to the last jar. These jars were stored, refrigerated in the laboratory, for repeated use. During the testing session, the child was instructed the following:

Now, we are going to play a "lollipop tasting game." In each of these jars is what we use to make lollipops. I will dip my lollipop stick in the jar, and then I will put a bit of the lollipop taste in your mouth, on your cheek and tongue. I want you to tell me what the lollipop tastes like. All three lollipops taste good, but they taste different. If you taste all three, you get to choose a prize to take home when we are all done today. Ready? First, let's taste this red lollipop. Open your mouth.

The examiner then put on gloves and dipped the sterile buccal swab into the solution in the jar. The examiner then briefly touched the child's tongue with the buccal brush and then firmly swabbed the inside of the child's cheek for at least four full strokes. The swab then was placed in the prepared solution in a vial to elute the DNA from the brush. The examiner then said, "What does it taste like? Yum, that was good." This procedure was repeated for the other two jars, using a new sterile swab for each dip into the respective jar, to yield a total of three samples. After all samples were obtained, the examiner asked the child which lollipop color was his or her favorite flavor and reminded the child about the toy at the completion of the testing session.

Using this new "Lollipop Tasting Game" procedure, complete buccal samples were obtained from $93 \%$ of the next 14 preschool children tested $(n=13)$. This sampling rate was significantly higher than without the "Lollipop Tasting Game" script (Fischer's exact $p<.04$ ). Therefore, this new collection procedure offers a simple, ethically sensitive method by which to obtain buccal samples for genotyping in preschool children, who developmentally are more proprietary of their bodies than school-age children. 


\section{ACKNOWLEDGMENTS}

This research was supported, in part, by Special Research Program and Undergraduate Research grants from the Office of Research Development and Administration, Southern Illinois University; and an award by the Rita Rudel Foundation to Kimberly Andrews Espy.

\section{REFERENCES}

Cook, E., Stein, M., Krasowski, M., Cox, N., Olkon, D., Kleffer, J., et al. (1995). Association of attention deficit disorder and the dopamine transporter gene. American Journal of Human Genetics, 56, 993-998.

Ebstein, R., Levine, J., Geller, V., Auerbach, J., Gritsenko, I., \& Belmaker, R. (1998). Dopamine D4 receptor and serotonin transporter promoter in the determination of neonatal temperament. Molecular Psychiatry, 3, 238-246.

Espy, K. A., Kaufmann, P. M., Glisky, M. L., \& McDiarmid, M. D. (2001). New procedures to assess executive functions in preschool children. The Clinical Neuropsychologist, 15, 46-58.

Gottlieb, G. (2001). The relevance of developmental-psycholobiological metatheory to developmental neuropsychology. Developmental Neuropsychology, 19, 1-10.

Sabol, S., Nelson, M., Fisher, C., Gunserath, L., Brody, C., Hu, S., et al. (1999). A genetic association for cigarette smoking behavior. Health Psychology, 18, 7-13. 